\title{
IDENTIFIKASI POTENSI DAN STRATEGI PENGEMBANGAN EKOWISATA PADA KAWASAN KONSERVASI HUTAN MANGROVE DESA PASAR BANGGI KABUPATEN REMBANG
}

\author{
Identification of Potential and Development Srategy of Ecotourism In Mangrove Forest \\ Conservation Area of Pasar Banggi Village Rembang Regency
}

\section{Aprilia Kukuh Dwijayati, Djoko Suprapto *), Siti Rudiyanti}

Program Studi Manajemen Sumberdaya Perairan

Fakultas Perikanan dan Ilmu Kelautan, Universitas Diponegoro

Jl. Prof. Soedarto, SH, Tembalang, Semarang, Jawa Tengah - 50275, Telp/Fax. +6224 7474698

Email : djapril.ad@gmail.com

\begin{abstract}
ABSTRAK
Desa Pasar Banggi memiliki potensi pariwisata hutan mangrove yang besar untuk dikembangkan. Tujuan dari penelitian ini untuk mengidentifikasi potensi, kesesuaian ekowisata dan menentukan strategi pengembangan ekowisata pada kawasan hutan mangrove Desa Pasarbanggi Kabupaten Rembang. Penelitian dilakukan pada tanggal 3-27 Juli 2016 di kawasan hutan mangrove Desa Pasar Banggi, Kabupaten Rembang. Metode yang digunakan dalam penelitian ini adalah deskriptif eksloratif, dengan menggunakan metode survei dalam bentuk data primer dan skunder. Data yang diperoleh kemudian dianalisis kesesuaian lahan dan analisis SWOT (Strength, Weakness, Opportunity dan Thread). Hasil penelitian menyatakan bahwa ketebalan hutan mangrove 100-150 ha dengan kerapatan bernilai $35-40$ ind $/ \mathrm{m}^{2}$. Potensi ekowisata yang terdapat pada kawasan hutan mangrove desa Pasarbanggi adanya jenis satwa dalam hal ini jenis burung yang dilindungi seperti kuntul kecil, dan kuntul kerbau.Hasil analisis kesesuaian ekowisata mangrove menunjukan pada stasiun I, II, dan III masingmasing adalah 67\%, 78\%, dan 70\% bahwa kawasan hutan mangrove dukuh Kaliuntu termasuk dalam kategori sesuai untuk dijadikan kawasan ekowisata di Kabupaten Rembang.Menurut hasil analisis SWOT, yang menjadi prioritas utama di Desa Pasar Banggi adalah: a) Penentuan zona dalam kawasan konservasi ekosistem mangrove dan b) Peningkatan partisipasi stakeholder terhadap program konservasi ekosistem mangrove.
\end{abstract}

Kata Kunci: Ekowisata; Hutan Mangrove; Pasar Banggi

\begin{abstract}
Pasar Banggi Village has tourism potential of mangrove forests to be developed. The purpose of this research was to identify the potential,analysis comformity of ecotourism and estabilsh the strategy of ecotourism development in the mangrove forest at Pasar Banggi area Rembang Regency. The research was conducted on July 3 - 27th 2016 in the mangrove forest Pasar Banggi Village, Rembang Regency. The method used in this research is descriptive explorative, by using survey method in a form of primary and secondary data. The collected data was then analyzed the conformitu of the land and SWOT analysis (Strangth. Weakness, Opportunity, and Thread). The result of the research showed that the thickness of mangrove forest is 100-150 ha with the density of 35-40 ind/ $\mathrm{m}^{2}$. The ecotourism potential that can be found in the mangrove forest at Pasar banggi village is the existence of protected bird such as little egrets and egrest buffalo. The result of the analysis comformity of ecotourism mangrove was shown in the station I, II, and III respectively are 67\%, 78\%, and 70\% that the mangrove forest area of Kaliuntu Village was include in suitable catagory to be targetted as the ecotourism area in Rembang Regency. Based on the SWOT analysis, the major priority in Pasar Banggi Village are: a) Determining zone in mangrove ecosystem concervational area, and b) The increase of stakeholders participation to the mangrove ecosystem concervational program.
\end{abstract}

Keywords: Ecotourism; Mangrove Forest; Pasar Banggi

*) Penulis Penanggung jawab

\section{PENDAHULUAN}

Kabupaten Rembang merupakan salah satu kabupaten yang berbatasan langsung dengan Laut Jawa. Kabupaten Rembang memiliki potensi pariwisata bahari yang cukup banyak. Salah satunya adalah wisata hutan mangrove yang terletak di Desa Pasar Banggi. Hutan mangrove Kabupaten Rembang memiliki luas kurang lebih 
60 ha sepanjang garis pantai di Desa Pasar Banggi, Rembang. Hutan mangrove tersebut di kelola oleh Kelompok Tani-Tambak dukuh Kaliuntu dan di awasi langsung dari Badan Lingkungan Hidup Kabupaten Rembang. Badan Lingkungan Hidup Kabupaten Rembang bertugas sebagai fasilitator dalam pengelolaan hutan mangrove yang ada di Desa Pasar Banggi. Setiap hari pengunjung dari warga sekitar mengunjungi lokasi hutan mangrove tersebut untuk sekedar berekreasi dan menikmati suasana hutan mangrove. Kondisi kawasan tersebut terdiri dari hutan mangrove yang cukup lebat serta aneka fauna langka dan cantik seperti burung bangau hitam dan putih serta masih banyak lagi. Wisata hutan mangrove Rembang terbilang masih baru yaitu terbentuk pada tahun 2013 dan masih banyak sekali kekurangan diantaranya tidak semua lokasi mangrove digunakan untuk lokasi wisata, serta pembukaan lahan untuk tambak.

Desa Pasar Banggi terletak di bagian utara Kabupaten Rembang, memiliki batas administratif di sebelah utara berbatasan langsung dengan Laut Jawa, sebelah selatan berbatasan dengan Desa Kandeman, sebelah barat dengan Desa Tireman dan sebelah timur berbatasan dengan Desa Tritunggal. Desa Pasar Banggi memiliki luas daerah administratif 410,905 ha, dengan panjang garis pantainya sekitar 3,5 km. Desa Pasar Banggi terbagi menjadi 2 dusun yaitu Dusun Banggi dan dusun Kaliuntu, memiliki 5 RW dan 15 RT. Menurut BPS Kabupaten Rembang (2016), pada tahun 2015 jumlah penduduk 4.657 jiwa terdiri dari 2.325 penduduk laki-laki dan 2.332 penduduk perempuan sehingga jumlah kepala keluarga sebanyak 924 KK. Profesi yang ditekuni antara lain peternak, petani, buruh tani, pengusaha kecil/menengah, pegawai negeri sipil (PNS), montir dan pedagang keliling. Mata pencaharian utama masyarakat Desa Pasarbanggi adalah nelayan.

Mengingat besarnya potensi hutan mangrove Rembang untuk dikembangkan menjadi objek wisata, maka perlu dilakukan identifikasi esesuaian lahan,faktor internal dan eksternal yang mempengaruhi pengembangan wisata mangrove di Pasar Banggi Rembang. Berdasarkankesesuan lahan, faktor internal dan eksternal tersebut maka selanjutnya akan dikembangkan strategi pengembangan wisata mangrove di Pasar Banggi, Rembang. Tujuan dilaksanakan penelitian ini adalah untuk mengidentifikasi potensi dan menentukan strategi pengembangan ekowisata pada kawasan hutan mangrove Desa Pasarbanggi Kabupaten Rembang.

\section{MATERI DAN METODE PENELITIAN Metode Pengumpulan Data}

Data yang digunakan dalam penelitian ini berupa data primer dan data sekunder.Data primer yang diperoleh adalah data mangrove dan organisme yang berasosiasi dengan eksosistem tersebut, data oseanografi, dan data sosial ekonomi masyarakat.Cara memperoleh data primer yaitu dengan menggunakan plot 10x10 m di tiga stasiun, kemudian mengukur ketebalan mangrove dengan roll meter, menghitung dan mengidentifikasi jumlah spesies mangrove, mendata obye biota yang berasosiasi dengan mangrove sepert ikan, udang, gastropoda, moluska, crustacea, dan burung. Kemudian dilakukan pengawetan dengan menggunakan formalin $4 \%$ selama $1 \times 24$ jam dan sampel diawetkan kembali dengn alkohol $70 \%$ untuk pengawetan jangka panjang untuk dilakukan identifikasi.

Data sosial ekonomi masyarakat diperoleh melalui pembagian daftar isian pertanyaan (kuisioner) dan wawancara. Jenis pertanyaan untuk kuesioner merupakan pertanyaan tertutup (closed endeed) diantaranya mengenai pengetahuan tentang mangrove, pemanfaatan mangrove, tanggapan masyarakat tentang wisata mangrove, dll. Metode yang digunakan dalam pengisian kuisioner adalah purposive sampling dimana responden ditentukan berdasarkan tujuan yang ingin diperoleh dari responden yang terdiri dari masyarakat setempat, pemerintah, nelayan, pengelola, dan pengunjung. Model wawancara yang digunakan adalah wawancara terstruktur dengan mengacu pada daftar pertanyaan yang disusun dan dianggap sesuai dengan aspek pengelolaan dan perencanaan pengembangan daerah.Data sekunder yang merupakan data penunjang yang diperoleh dari instansi-instansi terkait yaitu Dinas Kelautan dan Perikanan Kabupaten Rembang, BLH Kabupaten Rembang, Dinas Pariwisata Kabupaten Rembang, BPS Kabupaten Rembang mengenai data jumlah penduduk, dan BMKG megenai data pasang surut, dan lain-lain.

\section{Metode Analisis}

Berdasarkan jenis data yang dikumpulkan, penelitian ini menggunakan dua tahap proses analisis, yaitu analisis awal dan analisis lanjut. Analisis awal menggunakan dua metode yaitu kualitatif dan kuantitatif, sedangkan analisis lanjut menggunakan analisis SWOT (Salusu, 1996 dan Rangkuti, 2005).Adapun proses analisis data adalah sebagai berikut :

1. Analisis Kualitatif:

Metode penelitian kualitatif adalah metode untuk menyelidiki obyek yang tidak dapat diukur dengan angka-angka ataupun ukuran lain yang bersifat eksak. Teknik pengumpulan data deskriptif diantaranya adalah interview (wawancara) dan pengisian kuesioner. Metode yang digunakan untuk mengetahui kondisi sosial ekonomi serta budaya yang berkaitan dengan pengelolaan mangrove di kawasan tersebut. Tahap Analisis ini juga merupakan observasi awal yang menggambarkan keadaan mangrove dan juga dapat mengambarkan permasalahan yang ada di lokasi penelitian.

2. Analisis Kuantitatif

Adapun data mengenai kondisi ekologi berdasarkan plot pengamatan diolah untuk menganalisis kesesuaian wisata mangrove berdasarkan matrikskesesuaian di bawah ini :

${ }^{\top}$ Copyright by Management of Aquatic Resources (MAQUARES) 
Tabel 1. Matriks Kesesuaian Area Untuk Wisata Pantai Kategori Wisata Mangrove

\begin{tabular}{|c|c|c|c|c|c|c|c|c|c|c|}
\hline No & Parameter & Bobot & Kategori S1 & Skor & Kategori S2 & Skor & $\begin{array}{l}\text { Kategori } \\
\quad \text { S3 }\end{array}$ & skor & $\begin{array}{c}\text { Kategori } \\
\mathbf{N}\end{array}$ & skor \\
\hline 1. & $\begin{array}{c}\text { Ketebalan } \\
\text { mangrove }(\mathrm{m})\end{array}$ & 5 & $>500$ & 4 & $>200-500$ & 3 & $>50-200$ & 2 & $<50$ & 1 \\
\hline 2. & $\begin{array}{c}\text { Kerapatan } \\
\text { mangrove } \\
\left(100 \mathrm{~m}^{2}\right)\end{array}$ & 4 & $>15-25$ & 4 & $\begin{array}{c}>10-15 \\
>25\end{array}$ & 3 & $5-10$ & 2 & $<5$ & 1 \\
\hline 3. & $\begin{array}{c}\text { Jenis } \\
\text { mangrove }\end{array}$ & 4 & $>5$ & 4 & $3-5$ & 3 & $1-2$ & 2 & 0 & 1 \\
\hline 4. & $\begin{array}{l}\text { Pasang surut } \\
\text { (m) }\end{array}$ & 3 & $0-1$ & 4 & $>1-2$ & 3 & $>2-5$ & 2 & $>5$ & 1 \\
\hline 5. & Obyek biota & 3 & $\begin{array}{l}\text { Ikan, udang, } \\
\text { kepiting, } \\
\text { moluska, } \\
\text { reptil, burung }\end{array}$ & 4 & $\begin{array}{l}\text { Ikan, udang, } \\
\text { kepiting, } \\
\text { moluska }\end{array}$ & 3 & $\begin{array}{c}\text { Ikan, } \\
\text { moluska }\end{array}$ & 2 & $\begin{array}{l}\text { Salah satu } \\
\text { biota air }\end{array}$ & 1 \\
\hline 6 & Kekhasan & 1 & Internasional & 4 & Nasional & 3 & Provinsi & 2 & Lokal & 1 \\
\hline
\end{tabular}

Keterangan :

Nilai maksimum $=80$

Kategori Kesesuaian (\%)

$\mathrm{S} 1=$ Sangat sesuai, dengan nilai $>75-100 \%$

$\mathrm{S} 2=$ Sesuai, dengan nilai $>50-75 \%$

S3 $=$ Sesuai bersyarat, dengan nilai $>25-50 \%$

$\mathrm{N}=$ Tidak sesuai, dengan nilai $>25 \%$

Selanjutnya berdasarkan parameter-parameter kesesuaian area dalam tabel di atas, data yang diperoleh di lapangan diolah dengan menggunakan analisis data sebagai berikut :

\section{a. Ketebalan Mangrove / lebar mangrove}

Nilai yang didapatkan pada pengukuran ketebalan mangrove di lapangan adalah pengukuran lebar mangrove.

\section{b. Kerapatan Jenis}

Keterangan :

$$
D i=\frac{n i \bar{i}}{A}
$$

\section{$\mathrm{Di}=$ Kerapatan jenis (ind $/ \mathrm{m} 2)$ \\ ni $\quad=$ Jumlah total tegakan jenis $\mathrm{i}$ \\ A $\quad=$ Luas total area pengambilan contoh \\ c. Kekhasan / Keunikan (Uniquiness)}

Parameter ini dinilai dengan melihat keberadaan atau kekayaan jenis satwa atau tumbuhan pada suatu kawasan / habitat yang dinilai atau ekosistem di dalam suatu wilayah biogeografi atau pulau. Nilai kekhasan ini diperhitungkan dengan memperhatikan jenis satwa atau tumbuhan atau ekosistem yang dinilai terdapat di tempat lain atau tidak. Nilai yang diberikan untuk masing-masing tingkatan adalah :
Internasional / regional $=$ Sangat Unik
Nasional
$=$ Unik
Provinsi $\quad=$ Kurang Unik
Lokal $\quad=$ Tidak Unik

Selanjutnya penentuan Indeks Kesesuaian Wisata dengan menggunakan rumus sebagai berikut (Yulianda, 2007)

$$
I K W=2[\mathrm{Ni} / \mathrm{Nmaks}] \times 100 \%
$$

Dimana :

IKW = Indeks Kesesuaian Wisata

$\mathrm{Ni} \quad=$ Nilai Parameter ke-I (Bobot $\mathrm{x}$ Skor)

Nmaks $=$ Nilai maksimum dari suatu kategori wisata pantai.

\section{d. Analisis Potensi}

Analisis potensi merupakan analisis yang dinilai dengan melihat potensi biologi, potensi fisik baik aksesibilitas, infrastruktur, dan sarana prasarana, serta potensi amenitas. Kemudian menentukan bobot yang sesuai dengan keadaan lokasi wisata tersebut, dimana nilai : $4=$ sangat baik, $3=$ baik, $2=$ cukup, $1=$ Buruk. 


\section{e. Analisis SWOT}

Analisis SWOT merupakan tahap analisis lanjut. Berdasarkan hasil dari analisis deskriptif dan analisis kuantitatif, maka langkah selanjutnya adalah melakukan identifikasi faktor-faktor strategis untuk mengidentifikasi SWOT (Strength, Weakness, Opportunity, Threats).(Rangkuti, 2005 dan Salusu, 1996) :

Adapun langkah-langkah analisis SWOT sebagai berikut :

- Mengidentifikasi faktor-faktor strategis pengelolaan.

- Meingidentifikasi kekuatan (S), Kelemahan (W), Peluang (O), dan ancaman (T) dari hasil pengamatan yang dilakukan.

- Dari hasil identifikasi, dipilih 5 (lima) point yang dianggap penting dari setiap komponen SWOT diatas.

- Selanjutnya untuk menentukan strategi yang akan dijalankan dengan membuat matriks gabungan dari keempat komponen SWOT. Dari hasil matriks gabungan, kita dapat menentukan strategi dalam kelompok umum (SO, WO, ST, dan WT), yang selanjutnya akan terjabarkan dalam bentuk yang lebih spesifik.

Tabel 2. Standar Matriks Kombinasi SWOT (Rangkuti, 2005)

\begin{tabular}{|c|c|c|}
\hline EFAS & $\begin{array}{c}\text { Strengths }(\mathrm{S}) \\
\text { Tentukan } 2-10 \text { faktorfaktor } \\
\text { kelemahan } \\
\text { Internal }\end{array}$ & $\begin{array}{c}\text { Weaknesses }(\mathrm{W}) \\
\text { Tentukan } 2-10 \\
\text { faktor-faktor kekuatan } \\
\text { internal }\end{array}$ \\
\hline $\begin{array}{l}\text { Opportunities }(\mathrm{O}) \\
\text { Tentukan } 2-10 \\
\text { faktor-faktor } \\
\text { peluang eksternal }\end{array}$ & $\begin{array}{c}\text { Strategi (SO) } \\
\text { Ciptakan starategi yang } \\
\text { menggunakan kekuatan } \\
\text { untuk memanfaatkan } \\
\text { peluang }\end{array}$ & $\begin{array}{c}\text { Strategi (WO) } \\
\text { Ciptakan strategis } \\
\text { yang meminimalkan } \\
\text { kelemahan untuk } \\
\text { memanfaatkan } \\
\text { peluang }\end{array}$ \\
\hline $\begin{array}{c}\text { Treaths }(\mathrm{T}) \\
\text { Tentukan } 2-10 \\
\text { faktor - faktor } \\
\text { ancaman eksternal. }\end{array}$ & $\begin{array}{c}\text { Strategis (ST) } \\
\text { Ciptakan strategi yang } \\
\text { menggunakan kekuatan } \\
\text { untuk menghindari } \\
\text { ancaman }\end{array}$ & $\begin{array}{c}\text { Strategi (WT) } \\
\text { Ciptakan strategi } \\
\text { yang meminimalkan } \\
\text { kelemahan dan } \\
\text { menghidari ancaman }\end{array}$ \\
\hline
\end{tabular}

\section{HASIL DAN PEMBAHASAN}

Letak Geografis lokasi Konservasi Hutan Mangrove terletak di dukuh Kaliuntu, Desa Pasar Banggi, Kecamatan Rembang, Kabupaten Rembang, Jawa Tengah dengan posisi geografis 6041'52.45"- 6041'52.66" Lintang Selatan (LS) dan 111023'19.80' '111023'20.01' Bujur Timur (BT) (BLH Rembang, 2012). Batas-batas wilayah administratif Kabupaten Rembang yaitu di sebelah timur berbatasan dengan Kabupaten Tuban Jawa Timur, di sebelah selatan berbatan dengan Kabupaten Blora, sebelah batar berbatasan dengan Kabupaten Pati, dan sebelah utara berbatasan dengan Laut Jawa.Keadaan iklim Kabupaten Rembang memiliki kondisi cuaca berkisar antara $23^{\circ}-35^{\circ} \mathrm{C}$, dengan curah hujan $1.044 \mathrm{~cm} 3 /$ th. Faktor hidro-oseanografi di Kabupaten Rembang meliputi pasang surut, gelombang dan arus. Karakteristik dasar gelombang di sepanjang daerah perairan Kabupaten Rembang didasarkan dari 2 jenis angin musiman yang bertiup yaitu angin Muson Barat dan angin Muson Timur. Angin Muson Barat relatif labih besar hingga gelombangnya dapat mencapai ketinggian 2,5m (BAPPEDA Kabupaten Rembang, 2016).

\section{Parameter Ekowisata Mangrove di Hutan Mangrove Pasar Banggi}

1. Ketebalan Mangrove

Hasil yang didapat bahwa ketebalan tertinggi terdapat pada Stasiun II, hal ini menjadi daya tarik tersendiri bagi setiap pengunjung yang datang ke kawasan hutan mangrove Desa Pasar Banggi dengan luas mangrove 14,88 ha yang terhitung dari sepanjang garis pantai desa Pasarbanggi.Berdasarkan hasil penelitian dan pengukuran dari darat ke arah pantai yang dilakukan di kawasan hutan mangrove dukuh Kaliuntu maka diperoleh hasil pengukuran ketebalan ekosistem mangrove setiap stasiun pada grafik berikut: 


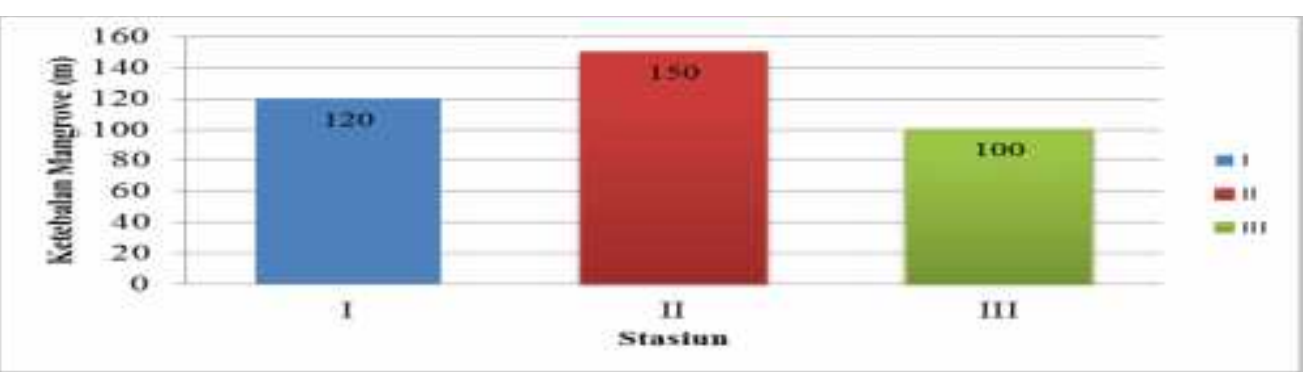

Gambar 1. Histogram Ketebalan Mangrove per Stasiun Pada Kawasan HutanMangrove Desa Pasar Banggi

2. Komposisi Jenis Mangrove

Berdasarkan hasil identifikasi yang dilakukan di lapangan dijumpai 1 Family mangrove yaitu Rhizophoraceae pada masing-masing transek. Spesies yang teridentifikasi antara lain : Rhizopora stylosa, Rhizophora mucronata, dan Rhzopora apiculata, untuk data jenis mangrove yang ditemukan di kawasan ekosistem mangrove dukuh Kaliuntu disajikan dalam Tabel 3.

Tabel 3. Komposisi Jenis Mangrove yang Dtemukan di Kawasan Hutan Mangrove Desa Pasar Banggi

\begin{tabular}{llll}
\hline Stasiun & Plot & Spesies & Jumlah Pohon \\
\hline I & 1 & Rhizophora mucronata & 35 \\
& 2 & Rhizophora mucronata & 25 \\
& 3 & Rhizophora stylosa & 20 \\
& & Rhizophora mucronata & 40 \\
\hline Total & 1 & Rhizophora stylosa & 120 \\
\hline II & 2 & Rhizophora apiculata & 31 \\
& 3 & Rhizophora mucronata & 12 \\
& & Rhizophora mucronata & 40 \\
& & & 35 \\
\hline Total & 2 & Rhizopora stylosa & 118 \\
\hline III & 3 & Rhizophora mucronata & 32 \\
& & Rhizophora mucronata & 35 \\
& &
\end{tabular}

Total

107

Ekosistem mangrove Desa Pasar Banggi, Rembang terdapat 5 jenis mangrove komponen mayor dan 5 jenis mangrove komponen asosiasi. Mangrove mayor yang ditemukan adalah Avicennia marina, Rhizophora apiculata, Rhizophora mucronata, Rhizophora stylosa dan Sonneratia alba. yang didominasi oleh mangrove jenis Rhizophora sp. Jenis mangrove mayor yang ditemukan di Desa Pasar Banggi relatif sedikit dibanding di Jepara yaitu 8 jenis atau Demak yaitu 6 jenis (Hastuti, 2013) dan sangat berbeda jauh dengan mangrove yang ditemukan di Teluk Bintuni, Papua yaitu 30jenis (Pribadi, 1998).

3. Kerapatan Jenis Mangrove

Berdasarkan hasil yang didapat kerapatan pada setiap Stasiun bervariasi. Stasiun II memiliki kerapatan yang lebih tinggi dibandingkan dengan Stasiun I dan Stasiun III, hal ini dikarenakan pada Stasiun II ditemukan 3 jenis mangrove yaitu Rhizophora apiculata,Rhizophora mucronata, dan Rhizophora stylosa, dimana pada plot ketiga menjadi area penanaman mangrove. Dengan demikian, kawasan mangrove dukuh Kaliuntu menjadi salah satu penyuplai oksigen yang besar sehingga setiap pengunjung yang berkunjung ke kawasan tidak hanya memperoleh informasi yang bersifat edukatif tetapi juga akan dapat menikmati udara segar yang cukup sulit dinikmati di perkotaan.

Tingkat keanekaragam dan keseragaman mangrove di Desa Pasar Banggi tergolong rendah. Penenaman yang dilakukan di Desa Pasar Banggi termasuk ke dalam monokultur, karena hanya menggunakan mangrove dari jenis Rhizophora sp baik Rhizophora apiculata, Rhizophora mucronata atau Rhizophora stylosa. Di Pantura Jawa Tengah rehabilitasi yang dilakukan sebagian besar menggunakan mangrove jenis Rhizophora sp dan yang paling sering dijumpai adalah dari jenis Rhizophora mucronata, sehingga di Pantura Jawa Tengah tergolong rehabilitasi monokultur, karena jenis Rhizophora sp adalah jenis mangrove yang paling mudah dikembangkan, dibudidayakan dan habitat hidupnya sesuai dengan karakteristik pesisir Pantura Jawa Tengah (Dinlutkan Jawa Tengah, 2012). 
Tabel 4. Nilai Kerapatan Jenis Vegetasi Mangrove

\begin{tabular}{|c|c|c|c|c|c|}
\hline Stasiun & Plot & Spesies & Jumlah Pohon & $\begin{array}{c}\text { luas area } \\
\text { (m) }\end{array}$ & $\begin{array}{c}\text { Kerapatan } \\
\left(\text { ind } / \mathbf{m}^{2}\right)\end{array}$ \\
\hline \multirow[t]{6}{*}{ I } & 1 & Rhizophora mucronata & 35 & 100 & 0,35 \\
\hline & 2 & Rhizophora mucronata & 25 & 100 & 0,25 \\
\hline & & Rhizophora stylosa & 20 & 100 & 0,2 \\
\hline & 3 & Rhizophora mucronata & 40 & 100 & 0,4 \\
\hline & & Total & 120 & 100 & 1,2 \\
\hline & & Rata-rata & & & 0,48 \\
\hline \multirow[t]{6}{*}{ II } & 1 & Rhizophora stylosa & 31 & 100 & 0,31 \\
\hline & & Rhizophora apiculata & 12 & 100 & 0,12 \\
\hline & 2 & Rhizophora mucronata & 40 & 100 & 0,4 \\
\hline & 3 & Rhizophora mucronata & 35 & 100 & 0,35 \\
\hline & & Total & 118 & 100 & 1,18 \\
\hline & & Rata-rata & & & 0,47 \\
\hline \multirow[t]{5}{*}{ III } & 1 & Rhizopora stylosa & 32 & 100 & 0,32 \\
\hline & 2 & Rhizophora mucronata & 35 & 100 & 0,35 \\
\hline & 3 & Rhizophora mucronata & 40 & 100 & 0,4 \\
\hline & & Total & 107 & 100 & 1,07 \\
\hline & & Rata-rata & & & 0,54 \\
\hline
\end{tabular}

4. Kondisi Pasang Surut

Berdasarkan data pasang dan surut didapatkan bahwa rata-rata pasang terjadi dengan ketinggian 1,1 m pada pukul 09.30 WIB , dan rata-rata surut terjadi dengan ketinggian 0,2 m pada pukul 18.20 WIB. Kondisi pada saat pengambilan data lapangan sedang pasang mulai jam 08.30 WIB. Pasang air laut terjadi pada pagi hari pukul 09.25 WIB dan kembali surut pada sore hari pukul 18.15 WIB.

5. Obyek Biota

a.Ikan

Tabel 5. Jenis Ikan Yang Ditemukan Pada Kawasan Hutan Mangrove Desa Pasar

\begin{tabular}{ll}
\hline Nama Latin & Nama Indonesia \\
\hline Chanos chanos & Ikan Bandeng \\
Periophthalmus sp. & Ikan Glodok
\end{tabular}

b.Burung

Tabel 6. Jenis Burung Yang Ditemukan Pada Hutan Mangrove Desa Pasar Banggi

\begin{tabular}{ll}
\hline Nama Latin & Nama Indonesia \\
\hline Egretta garzetta & Kuntul Kecil \\
Charadrius alexandrinus & Cerek Tilil \\
Bubulcus ibis & Kuntul Kerbau \\
Prinia familiaris & Prencak Jawa \\
\hline
\end{tabular}

c. Reptil

Tabel 7. Jenis Reptil Yang Ditemukan Di Kawasan Hutan Mangrove desa PasarBanggi

Nama Latin Nama Indonesia

Hydrophis belcheri Ular Laut cincin hitam

d.Crustacea
8. Jenis Crustacea Yang Ditemukan di Kawasan Hutan Mangrove dukuh Kaliuntu

Tabel $\frac{8 . \text { Jenis Crustacea Yang Ditemukan di Kawasan Hutan Mangrove dukuh Kaliun }}{\text { Nama Latin }}$

Scylla serrata $\quad$ Kepiting Bakau

Panaeus vannamei Udang Putih 
e.Moluska

Tabel 9. Jenis Moluska di Kawasan Hutan Mangrove dukuh Kaliuntu

\begin{tabular}{lll}
\hline Kelas & Famili & Spesies \\
\hline Gastropoda & Ellobiidae & Cassidula aurifelis \\
& Cotamididae & Cassidula nucleus \\
Melongenidae & Terebralia sulcata \\
Litoraridae & Melongenidae volema \\
& Litoraria melanostoma \\
& Litoraria intermedia \\
& Neritidae & Neritidae violacea \\
\hline
\end{tabular}

6. Kekhasan

Kekhasan merupakan salah satu parameter yang menentukan menarik tidaknya kawasan itu untuk dikembangkan menjadi kawasan ekowisata mangrove. Kawasan hutan mangrove dukuh Kaliuntu menjadi kawasan konservasi dan ekowisata pada tahun 2014 dengan perancanaan pada tahun 2013 (BLH, 2016). Hutan mangrove dukuh Kaliuntu menjadi tempat mencari makan, berbiak, ataupun sekedar tempat singgah atau beristirahat selama masa migrasi oleh burung-burung. Berdasarkan informasi dari warga setempat dengan berjalannya waktu hewan endemik yang biasanya bermigrasi jarang lagi terlihat sehingga berdasarkan hasil observasi di lokasi penelitian diperoleh nilai kekhasan lokal yang berarti tidak unik ditinjau dari sisi obyek biota yang terdapat di hutan mangrove tersebut seperti jenis burung yang ditemukan.

Analisis Kesesuaian Ekowisata Mangrve Desa Pasar Banggi

Tabel 14. Hasil Penilaian Kesesuaian Lahan Untuk Ekowisata Mangrove

\begin{tabular}{|c|c|c|c|c|c|c|c|c|}
\hline \multirow{3}{*}{ No } & \multirow{3}{*}{ Parameter } & \multirow{3}{*}{ Bobot } & \multicolumn{6}{|c|}{ Stasiun } \\
\hline & & & \multicolumn{2}{|c|}{$\mathbf{I}$} & \multicolumn{2}{|c|}{ II } & \multicolumn{2}{|c|}{ III } \\
\hline & & & Skor & Nilai & Skor & Nilai & Skor & Nilai \\
\hline 1 & Ketebalan Mangrove (m) & 5 & 2 & 10 & 2 & 10 & 2 & 10 \\
\hline 2 & Kerapatan Mangrove (ind/100m2) & 4 & 4 & 16 & 4 & 16 & 4 & 16 \\
\hline 3 & Jenis Mangrove & 4 & 2 & 8 & 2 & 12 & 2 & 8 \\
\hline 4 & Pasang Surut (m) & 3 & 3 & 9 & 4 & 12 & 3 & 9 \\
\hline 5 & Obyek Biota & 3 & 3 & 9 & 4 & 12 & 4 & 12 \\
\hline \multirow[t]{4}{*}{6} & Kekhasan & 1 & 1 & 1 & 1 & 1 & 1 & 1 \\
\hline & Jumlah & & & 53 & & 63 & & 56 \\
\hline & IKW (\%) & & & 67 & & 78 & & 70 \\
\hline & Kategori Kesesuaian & & & $\mathrm{S} 2 *$ & & $\mathrm{~S} 1 *$ & & $\mathrm{~S} 2 *$ \\
\hline
\end{tabular}

Keterangan:

*S1 = Sangat sesuai

$* \mathrm{~S} 2$ = Sesuai

Berdasarkan tabel diatas dapat disimpulkan bahwa nilai kesesuaian untuk stasiun I adalah 67\%, dan stasiun III 70\% dengan semua kategori adalah sesuai, sedangkan pada stasiun II 78\% dengan kategori sangat sesuai karena nilai indeks kesesuaian wisata $>75-100 \%$. Hal ini menunjukan bahwa pada stasiun II merupakan tempat yang sangat sesuai untuk dijadikan tempat wisata. Serta berdasarkan kategori kesesuaiannya maka dapat digunakan sebagai bahan pertimbangan dalam pengembangan kawasan untuk wisata yang lebih baik.Menurut Tuwo (2011) Kriteria ekologi mencakup keanekaragaman (kerapatan jenis, keanekaragaman spesies, dan keberadaan fauna), keunikan, biota berbahaya, keaslian, karakteristik kawasan (substrat dan genangan pasang), dan konservasi.

\section{Analisis Potensi}

a. Atraksi

Skor pada potensi atraksi yaitu 3 atau kategori baik, karena pada atraksi tersebut potensi flora hanya terdapat satu mangrove yang mendominasi dengan genus Rhizophora sehingga wisatawan hanya mengetahui satu jenis saja. Sedangkan potensi fauna semua terdapat di kawasan tersebut. Pembangunan jembatan dan gazebo menjadi nilai tambah untuk mendukung pengamatan wisatawan terhadap atraksi fauna.

b. Aksesibilitas

Pemberian skor untuk aksesibilitas adalah 3 atau kategori baik, hal ini dikarenakan akses jalan menuju ke lokasi hutan mangrove masih perlu diperhatikan mengingat jalan yang digunakan untuk masuk ke hutan mangrove merupakan jalan yang juga digunakan oleh para petani/penambak. Serta hanya dapat dilalui oleh satu orang saja. 
c. Amenitas

Penilaian untuk potensi amenitas adalah 2 atau kategori cukup hal ini dikarenakan sarana dan prasarana yang tersedia masih kurang dan perlu ditambah untuk memberikan kenyamanan bagi pengunjung misalnya jalan menuju lokasi, fasilitas kebersihan (toilet) dan area parkir yang layak menginat area parkir yang digunakan merupakan milik perorangan.

\section{Persepsi Stakeholder}

Pemilihan responden untuk pengisian kuisioner lebih mengacu pada representatifnya data. Jumlah responden dalam survei ini ditentukan langsung sesuai dengan kebutuhan. Walaupun demikian hal tersebut berdasar pada asumsi bahwa responden dalam hal ini masyarakat di Kawasan dukuh Kaliuntu adalah homogen, sehingga jumlah responden digeneralisasikan.

\section{Tujuan dan Frekuensi Kunjungan Responden ke Hutan Mangrove}

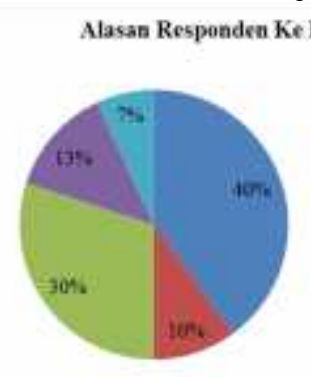

senikmati penarodangan

- Menikmati suasana terang dan nyamsi s Sekeder berfoto-foto - Menikmati ketndahat flora dan fauna = Menargkap kepiting

Frekuensi Kunjungan Respenden Ke Hutan Mangrove

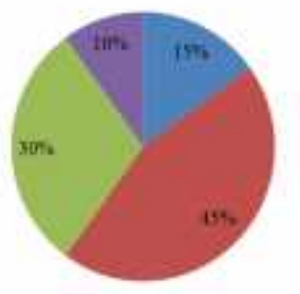

Setiaphar

- Bebetapa kati dalam sentingzu

- Beberapa bali dalam sebulan

- Beberapa kali dxiam setalusit

Gambar 2. Diagram Alasan Kunjungan Responden

ke Hutan Mangrove

Gambar 3. Diagram Frekuensi Kunjungan Responden ke Hutan Mangrove

Diagram alasan kunjungan responden di atas dapat diketahui bahwa $40 \%$ dari responden memiliki alasan berkunjung ke hutan mangrove karena untuk menikmati pemandangan. Selanjutnya 30\% dari responden memberikan alasan kunjungan ke hutan mangrove untuk sekedar berfoto-foto yang kemudian di upload di media sosial, $10 \%$ responden menjawab untuk menikmati suasana tenang dan nyaman di dalam hutan mangrove, $13 \%$ responden menjawab berkunjung ke hutan mangrove untuk menikmati keindahan flora dan fauna yang jarang ditemui oleh pengunjung, selebihnya $7 \%$ menjawab untuk menangkap kepiting oleh masyarakat sekitar untuk dijual sebagai mata pencarian tambahan.

Sedangkan, diagram frekuensi kunjungn responden di atas dapat diketahui bahwa $45 \%$ dari responden berkunjung ke hutan mangrove beberapa kali dalam seminggu biasanya pada saat hari sabtu - minggu oleh keluarga atau wisatawan dari luar daerah, 30\% dari responden berkunjung ke hutan mangrove bebrapa kali dalam sebulan biasanya pada saat hari libur nasional untuk menghabiskan waktu dengan teman atau keluarga, $10 \%$ dari responden berkunjung ke hutan mangrove beberapa kali dalam setahun biasanya oleh pengunjung yang bekerja atau kuliah di luar daerah Rembang pada saat libur lebaran, 15\% dari responden berkunjung ke hutan mangrove setiap hari biasanya pengunjung adalah warga sekitar dan pelajar sekitar lokasi wisata yang menghabiskan waktu untuk sekedar menikmati suasanya tenang dan nyaman.

\section{Analisis SWOT}

Tabel 10. Matrik Analisis SWOT

\begin{tabular}{|c|c|c|}
\hline IFAS & $\begin{array}{l}\text { Strengths }(\mathbf{S}) \\
\text { 1. } \\
\begin{array}{l}\text { Keanekaragaman jenis mangrove dan } \\
\text { biota yang cukup, masuk kategori } \\
\text { sesuai untuk pengembangan } \\
\text { ekowisata }\end{array} \\
\text { 2. } \quad \begin{array}{l}\text { Akses menuju ke lokasi mudah dan } \\
\text { terletak pada kawasan strategis dekat } \\
\text { dengan jalan Nasional }\end{array} \\
\text { 3. } \quad \begin{array}{l}\text { Aturan perundangan tingkat desa } \\
\text { yang mendukung usaha konservasi }\end{array}\end{array}$ & $\begin{array}{l}\text { Weaknesses }(\mathrm{W}) \\
\text { 1. Masih minimnya fasilitas pendukung wisata seperti } \\
\text { rumah makan, papan pengumuman, menara } \\
\text { pengawas,dan tempat persemaian bibit. } \\
\text { 2. Konsep detail wisata masih berupa master plan } \\
\text { yang belum berjalan } \\
\text { 3. Pengelolaan masih sangat sederhana, terbatas pada } \\
\text { retribusi parkir pengunjung }\end{array}$ \\
\hline  & \begin{tabular}{ll}
\multicolumn{1}{c}{ Strategi (SO) } \\
1. Meningkatkan kualitas sumberdaya \\
manusia terkait dengan ekowisata \\
2. Meningkatkan partisipasi stakeholder \\
terhadap program konservasi mangrove \\
3. Mendorong pengembngan wisata \\
khusus sepert pengamatan burung
\end{tabular} & $\begin{array}{l}\text { Strategi (WO) } \\
\text { 1. Pengadaan sarana dan prasarana penunjang } \\
\text { program konservasi ekosistem mangrove } \\
\text { 2. Menyusun konsep detail dari wisata mangrove } \\
\text { yang akan dikembangkan dengan menambah } \\
\text { atraksi budaya, kuliner atau cinderamta }\end{array}$ \\
\hline
\end{tabular}

${ }^{\circledR}$ Copyright by Management of Aquatic Resources (MAQUARES) 


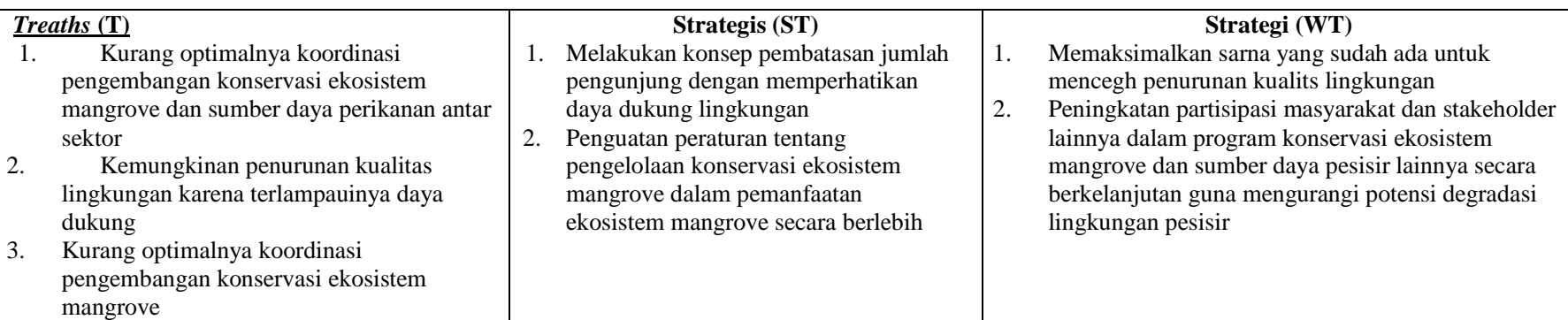

\section{Strategi Pengembangn Ekowisata Mangrove}

Strategi pengelolaan ekosistem mangrove yang menjadi prioritas utama di Desa Pasar Banggi adalah:

1. Penentuan zona dalam kawasan konservasi ekosistem mangrove di Desa Pasar Banggi

Penentuan zona dalam kawasan konservasi harus memperhatikan pemilihan dan penempatan kegiatan, alokasi sumberdaya alam serta alokasi ruang dengan memperhatikan aspek sumberdaya alam dan sumberdaya manusianya. Penentuan zona seperti zona inti dan zona pemanfaatan terbatas serta zona yang lainnya dalam upaya pelestarian mangrove. Penentuan zona dalam kawasan ekosistem mangrove Desa Pasar Banggi harus ditentukan karena dalam zona inti dilarang keras untuk melakukan kegiatan pemanfaatan dan dalam zonasi pemenfaatan terbatas hanya boleh melakukan kegiatan pemanfaatan sesuai dengan peraturan.

2. Peningkatan partisipasi stakeholder terhadap program konservasi ekosistem mangrove

Peran stakeholder sangat penting dalam kegiatan pengelolaan konservasi ekosistem mangrove di dukuh Kaliuntu, mengingat stakeholder sebagai pelaku pembangunan dan pengguna sumberdaya alam. Partisipasi stakeholder di Desa Pasar Banggi cukup baik sehingga dalam rangka pengelolaan konservasi ekosistem mangrove peran serta stakeholder harus terus ditingkatkan supaya kegiatan konservasi ekosistem mangrove dapat berjalan dengan baik. Stakeholder dalam hal ini terdiri dari pemerintah, lembaga non pemerintah, perguruan tinggi dan masyarakat. Keterlibatan masyarakat sangat penting mengingat masyarakat berinteraksi langsung dengan ekosistem mangrove.

\section{KESIMPULAN}

Kesimpulan yang dapat ditarik dar penelitian "Identifikasi Potensi dan Strategi Pengembangan Ekowisata

Pada Kawasan Konservasi Hutan Mangrove Desa Pasar Banggi Kabupaten Rembang” adalah sebagai berikut:

1. Potensi ekowisata di kawasan hutan mangrove Desa Pasar Banggi antara lain bentuk dari pohon mangrove, obyek bota seperti ikan, kerang, burung, gastropoda.

2. Hasil analisis kesesuaian ekowisata mangrove menunjukkan bahwa kawasan hutan mangrove Desa Pasar Banggi termasuk dalam kategori sesuai untuk dijadikan kawasan ekowisata di Kabupaten Rembang.

3. 3. Strategi pengembangan ekowisata mangrove Desa Pasar Banggi Rembang disimpulkan 2 skala prioritas yaitu:

a. Penentuan zona dalam kawasan konservasi ekosistem mangrove di Desa Pasar Banggi

b. Peningkatan partisipasi stakeholder terhadap program konservasi ekosistem mangrove.

\section{UCAPAN TERIMAKASIH}

Terimakasih kepada Dr. Ir. Suryanti, M.Pi, Dra. Niniek Widyorini, MS, Churun 'Ain, S.Pi, M.Si, dan Dr.Ir. Pujiono Wahyu Purnomo, M.S yang telah memberi masukan dan saran demi perbaikan penulisan artikel ini.

\section{DAFTAR PUSTAKA}

Bappeda Kab. Rembang. 2016. Laporan Akhir Rencana Tata Ruang Laut Kabupaten Rembang. Rembang.

BLH. 2016. Laporan Akhir Perencanaan Penyusunan Masterplan Hutan Wisata Mangrove Dukuh Kaliuntu Desa Pasarbanggi. Rembang

BPS Kab. Rembang. 2011. Kabupaten Rembang Dalam Angka. Rembang

Dinas Kelautan dan Perikanan Provinsi Jawa Tengah. 2012. Identifikasi Kerusakan dan Perencanaan Rehabilitasi Pantura Jawa Tengah. Semarang.

Hastuti, E, D. 2013. Interaksi Struktur Komunitas Vegetasi dengan Kualitas Lingkungan di Kawasan Sempadan Pantai Semarang-Demak. Disertasi. Pascasarjana Universitas Diponegoro. Semarang.

Rangkuti, F. 2005.Analisis SWOT Teknik Membedah Kasus Bisnis.PT. Gramedia Pustaka Utama. Jakarta.

Salusu, J. 1996. Pengambilan Keputusan Stratejik Untuk Organisasi Publik dan Organisasi Nonprofit. PT. Gramedia Widiasarana Indonesia. Jakarta.

Tuwo, A. 2011. Pengelolaan Ekowisata Pesisir dan Laut. Brilian Internasional. Surabaya. 